\title{
A study of assessment of infant feeding practices in urban slum of Bhopal, Madhya Pradesh, India
}

\author{
Tiwari A. ${ }^{1}$, Patel U. ${ }^{2}$, Singh D. ${ }^{3}$, Lakhwani S. ${ }^{4}$, Vishwakarma K. ${ }^{5}$ \\ ${ }^{1}$ Dr. Astha Tiwari, Associate Professor, ${ }^{2}$ Dr. Umesh Patel, Professor, ${ }^{3}$ Dr. Deepti Singh, Associate Professor, ${ }^{4}$ Dr. Sunita \\ Lakhwani, Associate professor, ${ }^{5}$ Dr. Kirti Vishwakarma, Assistant Professor, all authors are affiliated with Department of \\ Pediatrics, RKDF Medical College and Hospital Bhopal, Madhya Pradesh. India.
}

Corresponding Author: Dr. Astha Tiwari, Associate Professor, Department of Pediatrics, RKDF Medical College and Hospital, Bhopal, Madhya Pradesh. India. E-mail: ashutiwari23@gmail.com

\begin{abstract}
Background and Objective: Optimal breastfeeding and complementary feeding practices could reduce childhood morbidity and mortality dramatically in most cost-effective and efficacious way. Proper assessment of mothers knowledge regarding feeding practices and identifying the influencing factors that lead to faulty feeding practices is the need of the hour. Breastfeeding is of extreme importance for safeguarding health and welfare of growing infant and this practice must be preserved, protected and promoted by all means. with this background, this study was conducted to assess the infant feeding practices in urban slums and to determine the factors influencing it. Materials and Methods: A community based, cross sectional study conducted in urban slums in Bhopal. Madhya Pradesh for a period of 3 months A predesigned semi structured questionnaire using open and close ended questions were used to collect the information. Results: Out of the 170 mothers enrolled in the study, 53(31.17\%) mothers had started feeding within 1 hour of delivery. Prelacteal feed and colostrums was given to82 (48.23\%) and $61.76 \%$ respectively. Exclusive breastfeeding up to 6 months of age was $88(51.76 \%)$. Significant association was observed between maternal literacy and practice of EBF. and giving prelacteal feeds.51.76\% infants started receiving complementary feeding at right time .60(35.29\%) breast feeding knowledge and awareness was obtained by health personnel. Conclusion: This study shows that inappropriate feeding practices like giving prelacteals, discarding colostrums, delayed initiation of breastfeeding are prevalent in urban slums. Prevalence of exclusive breast feeding up to 6 months is less than the national level data. Awareness of mothers regarding correct feeding practices should be done at primary health care level.
\end{abstract}

Keywords: Breastfeeding, Infant feeding practices, Exclusive breastfeeding, Complementary feeding.

\section{Introduction}

Breastfeeding and complementary feeding practices have long been validated to have significant implications for maternal and child health. Healthy breastfeeding and complementary feeding practices reduce child mortality and morbidity besides being essential for their optimal growth and development [1].

WHO/UNICEF have emphasized the first 1000 days of life i.e, the 270 days in-utero and the first two years after birth as the critical window period for nutritional interventions. As the maximal brain growth occurs, malnutrition in this critical period can lead to stunting and suboptimal developmental outcome $[2,3]$.

Manuscript received: $30^{\text {th }}$ August 2019

Reviewed: $9^{\text {th }}$ September 2019

Author Corrected: $18^{\text {th }}$ September 2019

Accepted for Publication: $23^{\text {rd }}$ September 2019
According to the National Family Health Survey 3 data, about 20 million children are not able to receive exclusive breastfeeding (EBF) for the first six months, and about 13 million do not get good, timely and appropriate complementary feeding along with continued breastfeeding [4].

The National Family Health Survey (NFHS-4) has provided useful national- and state-level in-formation on the IYCF practices. Available data showed a gross inter-state variation [5].

NFHS-4 data at the national level \& also at Madhya Pradesh showed that only $41.6 \%$ \& $34.4 \%$ children under 3 year were put on breast-feeding within one hour of birth respectively. NFHS-4 data from Madhya 


\section{Original Research Article}

Pradesh have report-ed that 58.2\% children under 6 months are exclusively breastfed while only $38.1 \%$ children age 6-8 month receiving solid or semisolid food \& breast milk [5].

Overall, only $21 \%$ of breastfeeding and non-breastfeeding children were fed in accordance with the infant and young child feeding (IYCF) recommendation [3]. Almost one-fifth of overall under-five mortality can be averted if $90 \%$ of infants are covered with a package of intervention to protect, promote, and support the optimal Infant and young child feeding (IYCF) practices [6] Exclusive breastfeeding up to six months of age and breastfeeding up to 12 months established as top most preventative child survival interventions for their effectiveness in preventing under-five mortality followed by nutritionally- adequate, safe, ageappropriate complementary feeding starting at six months [6, 7]. These two interventions alone were estimated to prevent almost one-fifth of under-five mortality in developing countries [8].

Infant and Young child feeding which includes breastfeeding and complementary feeding practices, is comprised of various dimensions, namely, the type, the quality, the texture, the nutrient density, the frequency of feeding, and the diversity of the diet. Also the safety of food fed and the manner in which it is fed to the child are added dimensions to the whole spectrum of IYCF [9].

Early nutritional status, especially during the 1st year of life, has been shown to have a significant effect on child and adult health and development. Optimal infant feeding practices are crucial for nutritional status, growth, development, health, and ultimately the survival of infants and young children $[8,10]$.

Knowledge regarding time, consistency and quantity of complementary feeds depends on socio-economic conditions, literacy status of mother, traditions and belief [11] The infant feeding practices vary among the different regions and communities in India.

Frequent monitoring of changing trends in these practices in therefore necessary in societies in highly dynamic states of development.

Looking to the importance of infant feeding practices and with this background the present study was conducted with the objective to assess the Infant and feeding practices among infants less than one year of age in the slum areas.

\section{Objectives}

To know about the knowledge of mothers regarding breast feeding and complementary feeding.

To study about the infant feeding practice sand the factors influencing incorrect practices

\section{Materials and Methods}

It is a cross sectional observational study conducted in the urban slum areas present in outskirts of city of Bhopal between December 2017 to March 2018. It has a population around 8000 .

Data was collected from Anganwadi centers located in urban slum. $20 \%$ of the mothers of infants in the age group of 0-12 months attending the immunization session were selected and interviewed by the investigator personally and the relevant information was recorded using a pre-designed proforma semi structured questionnaire having open and close ended questions.

Questionnaire included child's age, order of birth, number of children in the family, place of delivery. Time of initiation, prelacteal feeds, number of times of feeding per day and duration of exclusive breastfeeding was noted.

Positioning of the baby and signs of attachment was observed and noted as per IMNCI guidelines. Timing of initiation of complementary feeding, mode of feeding the child, advice received from health worker, problem faced when introduced complementary feeding were noted.

\section{Method of collection of Data}

Sample size: Considering the exclusive breastfeeding rate of $54.9 \%$ (according to NFHS 4) the sample size was calculated using the formula $\mathrm{pq} / \mathrm{L} 2$ where ( $\mathrm{p}$ is the prevalence of $\mathrm{EBF}=54.9 \mathrm{q}$ is $(\mathrm{i}-\mathrm{p})$ is 45.1 , ( $\mathrm{L}$ is the allowable error of $20 \%$ ) a sample size of 85 was calculated, As the sample size was less for the study. sample size was doubled to make the study more significant.

So, sample size is increased to 170.170 mothers having infants under 12 months of age were selected by simple random sampling from 4 Anganwadis in the urban slums.

Inclusion criteria: Mothers of infants (less than one year) in the urban slum 


\section{Original Research Article}

\section{Exclusion criteria}

1. Mother unwilling to give consent

2.Any illness of the infant affecting feeding as diagnosed by the attending pediatrician

3. Contraindications to breastfeeding.

\section{Results}

Table-1: Baseline data of mother and infants.

\begin{tabular}{|c|c|c|}
\hline Variable & Number $(n=170)$ & Percentage \\
\hline \multicolumn{3}{|l|}{ Age Group } \\
\hline$\leq 20$ years & 34 & 20 \\
\hline $21-25$ years & 78 & 45.88 \\
\hline $26-30$ years & 36 & 21.17 \\
\hline$>30$ years & 22 & 12.94 \\
\hline \multicolumn{3}{|l|}{ Religion } \\
\hline Hindu & 149 & 87.6 \\
\hline Muslim & 15 & 8.8 \\
\hline Others & 6 & 3.5 \\
\hline \multicolumn{3}{|l|}{ Literacy } \\
\hline Illiterate & 68 & 40 \\
\hline Literate & 102 & 60 \\
\hline \multicolumn{3}{|l|}{ Place of Delivery } \\
\hline Institutional & 146 & 85.88 \\
\hline Home & 24 & 14.11 \\
\hline \multicolumn{3}{|c|}{ Working status of mother } \\
\hline Working & 59 & 34.7 \\
\hline Non-working & 111 & 65.29 \\
\hline \multicolumn{3}{|l|}{ Infants Age } \\
\hline 0-6 months & 56 & 32.94 \\
\hline $7-9$ months & 46 & 27.05 \\
\hline $9-12$ months & 68 & 40 \\
\hline \multicolumn{3}{|l|}{ Gender } \\
\hline Male & 86 & 50.58 \\
\hline Female & 84 & 49.41 \\
\hline \multicolumn{3}{|l|}{ Birth order } \\
\hline First & 72 & 42.35 \\
\hline Second & 86 & 50.58 \\
\hline Third and above & 12 & 7.05 \\
\hline
\end{tabular}

General profile: In the present study number of mothers of infants upto $1 \mathrm{yr}$ of age were 170. Maximum were in age group of 21-25yrs 78 (45.8\%) Out of 170 infants, boys were $86(50.58 \%)$ and girls were $84(49.41 . \%)$ with a ratio of 1:0.95. Infants under 6 months were 56(32.94\%).,7-9 months were 46(27.05\%) First born were $42.35 \%$

Socio-demographic profile- Among 170 mothers 149 (87.6\%) were Hindus. Nearly 40\% of mothers were illiterate, 60\% were literate. Nearly $146(85.88 \%)$ deliveries were institutional and about $24(14.11 \%)$ were home deliveries attended by trained dais. Working mothers were $59(34.7 \%)$ and non-working were $111(65.29 \%)$ 
Table-2: Various feeding practices observed in study.

\begin{tabular}{|l|c|c|}
\hline Feeding practice & Number & Percentage \\
\hline Use of Pre-lacteals & 82 & 48.23 \\
\hline Cow milk & 48 & 58.5 \\
\hline Formula milk & 11 & 13.4 \\
\hline Sugar, honey, boiled water & 23 & 28 \\
\hline Initiation of feeding within 1 hour & 105 & 31.17 \\
\hline Regarding Colostrum feeding & 88 & 61.76 \\
\hline Exclusive Breastfeeding up to 6 months & 130 & 51.76 \\
\hline BF during illness & 78 & 76.47 \\
\hline Bottle feed & & 45.88 \\
\hline
\end{tabular}

Breastfeeding practices: In the present study all 170 (100\%) infants were breastfed. Pre lacteal feeds were given to 82 $(48.23 \%)$ infants, out of which $58.5 \%$ were given cow's milk. Sugar honey and water was given to $28 \%$ infants as prelacteal feed. Formula milk was given in 11 (13.4\%). 45.88\% used bottle feeding.

Among $54(34.2 \%)$ illiterate mothers 44(81.5\%) mothers were administering pre lacteal feeds showing a positive significant association between illiteracy among mothers and administration of pre lacteals $(\mathrm{X} 2=20.12, \mathrm{P}=<0.0001)$ (Table-6).

Breastfeeding was initiated within 1 hour of birth in 53(31.17\%). The reasons of delayed initiation of breast feeding after delivery were that majority of mother 36(34.28\%) had undergone surgery or had a delayed initiation of lactation 20(19.04\%). Baby admitted in NICU was the reason in $18(17.14 \%)$ Nearly $9.02 \%$ of mothers were not aware of early initiation of breastfeeding. Colostrum was given to 105(61.76\%) infant. (Table-3) Exclusive breastfeeding for 6 months is seen in 88 (51.76\%). Among 55 (32.35\%) illiterate mothers, majority of them $46(86.63 \%)$ have not practiced exclusive breastfeeding for 6 months and is found to be statistically significant $(\mathrm{P}=<0.0001)$. (Table -6$)$. In the majority of mothers $60(35.29 \%)$ breastfeeding knowledge and awareness was obtained by health personnel during regular antenatal and immunization visits in anganwadis and health centers. From family 42(24.70\%). 8(4.7\%) mothers had no knowledge regarding early initiation of breast feeding. (Table 4)

Table-3: Reasons for late initiation of breastfeeding.

\begin{tabular}{|l|c|c|}
\hline Reason & Number $(\mathbf{n = 1 0 5})$ & Percentage \% \\
\hline Milk not produced immediately & 20 & 19.04 \\
\hline Delivery Complication** & 21 & 20 \\
\hline Baby was in NICU & 18 & 17.14 \\
\hline Caesarian section & 36 & 34.28 \\
\hline Not aware of early Initiation & 10 & 9.52 \\
\hline
\end{tabular}

Table-4: Source of breast-feeding related knowledge in mothers $(n=170)$

\begin{tabular}{|c|c|}
\hline Source & Numbers (\%) \\
\hline School & $\mathbf{3 4}(\mathbf{2 0})$ \\
\hline Health personnel & $\mathbf{6 0}(\mathbf{3 5 . 2 9})$ \\
\hline Family & $\mathbf{4 2}(\mathbf{2 4 . 7 0})$ \\
\hline Media & $\mathbf{2 6}(\mathbf{1 5 . 2 9})$ \\
\hline No knowledge & $\mathbf{8}(4.7)$ \\
\hline
\end{tabular}


Table-5: Complementary Feeding Practices.

\begin{tabular}{|l|c|c|}
\hline Practices & Number $(\mathbf{n}=\mathbf{1 7 0})$ & Percentage \% \\
\hline Appropriate time of initiation & & \\
\hline $0-4$ months & 12 & 7.05 \\
\hline $4-6$ months & 51 & 30 \\
\hline $6-9$ months & 88 & 51.76 \\
\hline $9-12$ months & 19 & 11.17 \\
\hline Appropriate consistency & 55 & 32.35 \\
\hline Appropriate amount & 89 & 52.35 \\
\hline Adequate frequency & 82 & 48.23 \\
\hline
\end{tabular}

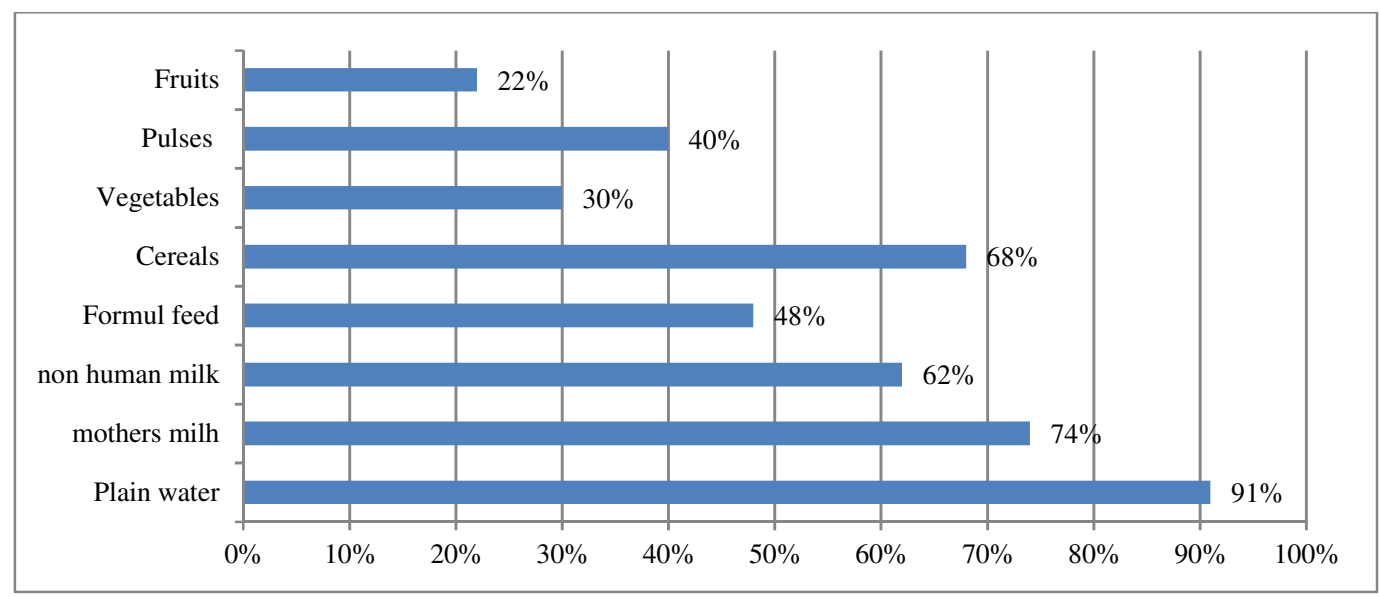

Figure-1: Complementary feeding practices age 6-12 months

Complementary feeding was introduced before 6 months of age in 63 (37.05\%) of infants and at 6 months in 88 $(51.76 \%)$. In 19(11.17\%) of infants complementary was started late between 9-12 months. Continuation of breastfeeding was seen in $74 \%$ infants. In Spite of higher cost of formula feed $50 \%$ of mothers are giving formula feeds which should be discouraged. $48 \%$ mother gave cereals, vegetables and pulses were given to $30 \%$ and $40 \%$ infants as a complementary feeding (Figure 1) $32.35 \%$ of infants were given feeding inappropriate consistency. Complementary feeding was given in appropriate amount and frequency in $89(52.35 \%)$ and $82(48.23 \%)$ respectively.

Table-6: Association of exclusive breastfeeding and Pre lacteal feeds with literacy status of mother

\begin{tabular}{|c|c|c|c|}
\hline & \multicolumn{2}{|c|}{ Exclusive Breast Feeding } & \multirow[b]{2}{*}{ Total } \\
\hline & Yes & No & \\
\hline Illiterate & $15(27.27 \%)$ & $40(72.72 \%)$ & 55 \\
\hline Literate & $73(63.47 \%)$ & $42(36.53 \%)$ & 115 \\
\hline Total & 88 & 82 & 170 \\
\hline \multicolumn{4}{|c|}{ The chi-square statistic is 19.5327 . The $p$-value is .00001 . This result is significant at $p<0.05$} \\
\hline \multicolumn{4}{|c|}{-Prelacteals } \\
\hline & Yes & No & \\
\hline Illiterate & 46 & 9 & 55 \\
\hline \multirow[t]{2}{*}{ Literate } & 36 & 79 & 115 \\
\hline & 83 & 87 & \\
\hline
\end{tabular}




\section{Original Research Article}

Among 55 (34.2\%) illiterate mothers 46(81.5\%) mothers were administering pre lacteal feeds showing positive significance $(\mathrm{X} 2=18.1623(\mathrm{P}=<0.0001)$. Exclusive breastfeeding for 6 months is seen in $88(51.76 \%)$ Among 55 (32.35\%) illiterate mothers, majority of them $40(72.27 \%)$ have not practiced exclusive breastfeeding for 6 months and is found to be statistically significant. $(\mathrm{P}=<0.0001)$

\section{Discussion}

Two practices together - ensuring optimal breastfeeding in the first year and complementary feeding practices could prevent almost one fifth of deaths of children under 5 years of age [12-14].

The urban population is rapidly expanding because of the large-scale migration of people to the cities and it is projected that more than half of the Indian population will live in urban areas by 2020 and that nearly one third of this urban population would have been slum dwellers previously [15]. The ongoing process of rapid urbanization has deleterious repercussions on the health and nutrition, especially in children. Inappropriate infant feeding practices is one of the important causes of malnutrition as has been reported by a study [16].

The present study revealed that initiation of breastfeeding within $1 \mathrm{~h}$ of birth was seen in $31.17 \%$ which is less than the corresponding both national $(41.6 \% \%)$ and Madhya Pradesh (34.4\%) NFHS-4\% [5]. statistics. We also found lower percentage initiation of breastfeeding was reported by other studies from urban slum areas i.e. A Dasgupta et.al (31.4\%), (348.1\%) Raval D et al. while a higher $66 \%$ was reported in Swati et al, this difference may be due to local culture beliefs and practices that existed in particular regions [17, 18, 19]. Ghana study which clearly showed for the first time in the world, that ensuring initiation of breastfeeding within 1 hour could cut $22 \%$ of all neonatal mortality [20]. That means in India, if all mothers were enabled to initiate breastfeeding within the 1st hour, about 2.5 lac deaths occurring during 1st month could be saved [21].

Some studies have identified cesarean section as a hindering factor in this regard $[17,18]$. In the present study caesarian section was seen as the main reason $(34.28 \%)$ for late initiation of breastfeeding.

In the present study it was observed that the prevalence pre-lacteal feed was $(48.23 \%)$ other reported $(31.4 \%)$, Nagpur slum (78.61\%), and a study at Gujarat (61.9\%), Garhwal region $(33.6 \%)$ [17, 18, 22, 23]. In the present study most common prenatal feed was cow's milk $(61.53 \%)$. Colostrum was given to $61.76 \%$ of the babies. Variable results are seen in other studies $(36.9 \%)$ by Dewang et al, Aparajita Dasgupta et.al $(70.9 \%)[17,18]$.
Among 55 (34.2\%) illiterate mothers 46(81.5\%) mothers were administering pre lacteal feeds showing a positive significant association ( $\mathrm{X} 2=18.1623$ $(\mathrm{P}=<0.0001)$. Association between maternal illiteracy and use of prelacteal. Similar result was seen in studies $[18,22]$.

This indicates that prelacteal feeding is still prevalent across the nation due to cultural prejudice, maternal illiteracy and false belief even after health promotion. All efforts must be made both at institution and domiciliary level to remove this unhealthy practice.

Exclusive breastfeeding among children less than 6 months: Exclusive breastfeeding under 6 months of age was found in $51.76 \%$ in the present study which is less than NFHS-4 data at national level (54.9\%) and at state level Madhya Pradesh (58.2\%) and also from other studies like in Kolkata (66.7\%), Garhwal region $(52.8 \%)$ [5, 17, 24]. Study in urban slums in Nagpur (36.84\%) and Karnataka (Rajesh et al) (22\%) showed less percentage of mother practicing exclusive breast feeding [22].

Data from urban slums repeatedly documented that although breastfeeding was common, exclusively breast feeding was practiced only in $30-40 \%$ of infants younger than 4 months of age.[24]

A statically significant association was seen between EBF and maternal literacy in present study. Similar significant association of exclusive breastfeeding and maternal literacy is seen in other studies. In a. Similar study at Nagpur, Bagul et al noted $84 \%$ of literate mothers had practiced EBF and only $24 \%$ of illiterate mothers had done EBF practice to babies [22]. Complementary feeding was introduced before 6 months of age in $63(30.07 \%)$ of infants and at the appropriate age in $88(51.76 \%)$. In $19(11.17 \%)$ of infants complementary was started late between 9-12 months.

According to NFHS Madhya Pradesh data children under 6-8 months receiving solid or semisolid food and breast milk were $38.1 \%$ Aparajita et al reported complementary feeding was found to be started $21.2 \%$ both at less than 6 months and at 6 months and $17.6 \%$ at 


\section{Original Research Article}

more than 6 months of age $[4,5,17]$. Health personnel $(35.29 \%)$ and family members were the main source of information regarding feeding practices for our mothers. Similar observation noted by Roy et al. in a study at Kolkata [17, 23]. $34.22 \%$ of respondents were informed about infant feeding practices by health personnel in their study. so, adherence to the correct feeding practices can be increased by promoting education to mothers and by imparting health education.

Limitations of the study: In the study the subjects were from the population attending health centers (Anganwadis) and hence it may not be a representative of the general population. The small sample size for proportion for children for various age groups limits its representativeness. A study with more sample size and with better statistical tools needs to be done.

\section{Conclusion}

The conclusion of the study is that undesirable practices related to infant feeding such as late initiation of breastfeeding, discarding colostrum, use of prelacteal feeding, and inappropriate complementary feeding practices are still prevalent. Low rates of exclusive breastfeeding found in the study whichis below national and state statistics. is an area of concern.

Maternal illiteracy and lack of awareness regarding correct feeding practices were the limiting factors for faulty feeding practices. Various parameters are improving but still much remains to be done at primary care level.

A comprehensive and effective plan and activities needs to be prepared to promote, maternal counseling, development of lactation clinics, and training of health workers and relevant programs at community level. Awareness among mothers regarding the importance and advantages of colostrum feeding, early initiation of breast feeding, exclusive breast feeding for 6 months, introduction of complementary feeding at 6 months, harmful effects of prelacteal feeding should be created to improve the health of children in early years of life

\section{What this study adds to existing knowledge?}

This study shows that most indicators showed improvement compared to the previous but the faulty feeding practices are still prevalent and are not reasonable and need to be corrected. the finding in the study clearly highlight the importance of mother's education on infant feeding practices.

\section{Author's contribution}

1. Dr. Astha Tiwari: The concept and design of the study, Statistical analysis of data analysis, manuscript preparation, editing, and review. and final approval of the version to be submitted.

2. Dr. Umesh Patel, Dr. Deepti Singh, Dr. Sunita Lakhwani, Dr. Kirti Vishwakarma: Acquisition of data, search of literature and interpretation of data.

Funding: Nil, Conflict of interest: None initiated, Permission from IRB: Yes

\section{References}

1. World Health Organization. Infant and young child feeding: Model chapter for textbooks for medical students and allied health professionals.

2. National guidelines on Infant and Young Child Feeding. Ministry of Human Resource Development. Department of Woman and Child Development. (Food and Nutrition Board). Government of India. 2004. Available: https://wcd.nic.in/sites/default/files/national guidelines.pdf

3. Tiwari S, Bharadva K, Yadav B, Malik S, Gangal P, Banapurmath CR et al. IYCF Chapter of IAP 70. Infant and Young Child Feeding Guidelines. 2016;53(8):703713.

4. National Family Health Survey 2005-2006 (NFHS-3).Mumbai: International Institute of Population Sciences. Available at http://www.nfhsindia.org.

5. National Family Health survey (NFHS4): http://www.indiaenvironmentportal.org.in/content/4403 96/national-family-health-survey-2015-16-nfhs-4-indiafact-sheet.

6. Jones G, Steketee RW, Black RE, Bhutta ZA, Morris SS; Bellagio Child Survival Study Group. How many child deaths can we prevent this year? Lancet. 2003;362 (9377):65-71. doi:10.1016/S0140-6736(03)13811-1

7. WHO/UNICEF. Global Strategy for Infant and Young Child Feeding. 2003. Available at:https://www. unicef.org/nutrition/files/GlobalStrategy_Infant_and_ Young_ChildFeeding.

8. Black RE, Bhutta ZQA, Caulfi LE, Onis Md, Ezzati M, Mathers C, et al. Maternal and child undernutrition global and regional exposures and health consequences. Lancet. 2008;371(9608):243-260. doi: https://doi.org/ 10. 1016/S0140-6736(07)61690-0 


\section{Original Research Article}

9. Srivastava N, Sandhu A. Infant and child feeding index. Indian J Pediatr. 2006;73(9):767-770. doi:10. 1007/ bf02790382

10. Saha KK, Frongillo EA, Alam DS, Arifeen SE, Persson LA, Rasmussen KM. Appropriate infant feeding practices result in better growth of infants and young children in rural Bangladesh. Am J Clinic Nutri. 2008;87(6):1852-1859. doi: 10.1093/ajcn/87.6.1852

11. Aggarwal A, Verma S, Faridi MM. Complementary feeding-reasons for inappropriateness in timing, quantity and consistency. Indian J Pediat. 2008;75(1): 49-53. doi: https://doi.org/10.1007/s12098-008-000 6-9

12. Improving Child Nutrition: The achievable imperative for global progress. UNICEF Doi: https:// www. unicef. org/nutrition/index_68661.

13. Wadde SK, Vedpathak VL, Yadav VB. Breast feeding practices in rural mothers of Maharashtra. Int J Recent Trends Sci Tech. 2011;1(3):115-119.

14. Rathaur VK, Pathania M, Pannu C, Jain A, Dhar M, Pathania N, Goel R. Prevalent infant feeding practices among the mothers presenting at a tertiary care hospital in Garhwal Himalayan region, Uttarakhand, India. J Fam Med Primary Care. 2018;7(1):45.

15. National Family Health Survey (NFHS-2), India, 1998-99. Mumbai: International Institute for Population Sciences and ORC Macro; 2000 Available at: https:// hetv.org/pdf/nfhs/india/indintro.

16. Ghosh S, Shah D. Nutritional problems in urban slum children. Indian Pediatr. 2004;41(7):682-696.

17. Dasgupta A, Naiya S, Ray S, Ghosal A, Pravakar R, Ram P. Assessment of Infant and Young Child Feeding
Practices among the Mothers in a Slum Area of Kolkata: A Cross Sectional Study. Int J Biol Med Res. 2014;5(1):3855-3861.

18. Raval D, Jankar D, Singh M. A study of breastfeeding practices among infants living in slums of Bhavnagar city, Gujarat, India. Health, J Indian Associat Prevent Social Med. 2011;78(5.44):1-19.

19. Jain S, Borle A, Agrawal SS, Mishra MK, Gupta SK, Bathma V. Assessment of Infant and Young Child Feeding Practices Among Mothers in Rural Madhya Pradesh. National J Commun Med. 2014;5(4):419-423.

20. Edmond KM, Zandoh C, Quigley MA, AmengaEtego S, Owusu-Agyei S, Kirkwood BR. Delayed breast-feeding initiation increases risk of neonatal mortality. Pediatr. 2006;117(3): e380-e386. doi:10. 1542 / peds. 2005-1496.

21. 11th Five Year Plan Report of Working Group on Integrating Nutrition with Health; Government of India, Ministry of Women and Child Development; 2006.p. 13 Available at https://motherchildnutrition.org/india.

22. Bagul AS, sahebrao Supare M. The infant feeding practices in an urban slum of Nagpur, India. Journal of clinical and diagnostic research: JCDR. 2012;6(9): 1525-1527. doi: 10.7860/JCDR/2012/4622.2549

23. Roy S, Dasgupta A, Pal B. Feeding practices of children in an urban slum of kolkata. Indian J Community Med. 2009;34(4):362-363. doi: 10.4103/ 0970-0218.58402.

24. Aneja B, Singh P, Tandon M, Pathak P, Singh C, Kapil U. Etiological factors of malnutrition among infants in two urban slums of Delhi. Indian Pediat. 2001; 38(2):160-165.

\section{How to cite this article?}

Tiwari A, Patel U, Singh D, Lakhwani S, Vishwakarma K. A study of assessment of infant feeding practices in urban slum of Bhopal, Madhya Pradesh, India. Int J Pediatr Res.2019;6(09):436-443.doi:10.17511/ijpr. 2019.i09.01 